Z Gerontol Geriat 2015 · 48:176-183

DOI 10.1007/s00391-014-0668-z

Received: 6 December 2013

Revised: 5 May 2013

Accepted: 12 May 2013

Published online: 4 February 2015

c) Springer-Verlag Berlin Heidelberg 2015

\author{
A. Koppitz ${ }^{1}$ G. Bosshard ${ }^{2}$ D.H. Schuster ${ }^{1} \cdot$ H. Hediger ${ }^{1} \cdot$ L. Imhof ${ }^{1}$ \\ ${ }^{1}$ Institute of Nursing, Zurich University of Applied Sciences (ZHAW), Winterthur \\ ${ }^{2}$ Clinic for Geriatric Medicine, and Center on Aging and Mobility, \\ University Hospital of Zurich, University of Zurich, Zurich
}

\title{
Type and course of symptoms demonstrated in the terminal and dying phases by people with dementia in nursing homes
}

canton of Zurich) was designed to look at the course of symptoms in patients with dementia in nursing homes during the last 90 days of life.

The present paper addresses the following questions:

- What symptoms are noted in the nursing homes' records for people with dementia in their terminal phase, and with what frequency?

- What particular features are displayed by people with dementia in the dying phase-defined as the last 7 days of life-in nursing homes?

\section{Methodology}

\section{Design}

This exploratory study follows a retrospective, descriptive design [11]. The nursing records of 65 deceased people with dementia from nursing homes in the canton of Zurich, Switzerland, were analysed.

\section{Setting}

Four nursing homes which specialised in caring and nursing of people suffering from dementia were selected for the study by means of a convenience sample. Nursing home 1 has places for 103 people, nursing home 2 for 91 people, nursing home 3 for 249 people, and nursing home 4 for 28 people.

\section{Data collection}

The study [11] included people who died in the years 2011 and 2012 and in which dementia had been documented by statements from nursing professionals. This was the case in a total of 65 people. The last 90 days of life were divided up into four analysis periods ( Tab. 1). The decision to study the last 90 days of life was based on the works of Kiely et al. [12] and Volicer et al. [13]. It is in this stage of life that the degenerative process and the associated manifestation of symptoms are most evident. The last 7 days of life were categorised as the dying phase.

Symptoms are defined as experiences that were identified both subjectively and objectively [14]. The associated signs or features, such as reduced appetite, may be assessed as objective and/or subjective indications of a nursing problem or as indicators of an illness. The aetiological grounds for a symptom may be of a pathophysiological nature and/or may be due to behaviour or to unfulfilled psychosocial needs or other environmental factors [15]. Definitions of the variables used are shown in $\bullet$ Tab. 2. The items described therein are based on the docugeted interventions [10]. Therefore, the Pallhome study (Palliative care for people with dementia in nursing homes in the

1 The term nursing home in this study encompasses both nursing homes and old people's homes.

\begin{tabular}{|lllll|}
\hline Tab. 1 & Analysis periods & & & \\
\hline Point of data collection $(=\mathrm{T})$ & T1 & T2 & T3 & T4 \\
\hline Days & $90-61$ & $60-31$ & $30-8$ & 7 -day of death \\
\hline & Terminal phase & & Dying phase \\
\hline
\end{tabular}




\begin{tabular}{|c|c|}
\hline Variables & Items \\
\hline $\begin{array}{l}\text { Sociodemo- } \\
\text { graphic data }\end{array}$ & Age, gender, family situation, length of stay in nursing home \\
\hline Anxiety [15] & $\begin{array}{l}\text { Feeling of discomfort or threat that occurs episodically and is characterised by } \\
\text { inner tension, voiced fears and/or nervousness }\end{array}$ \\
\hline Apathy [16] & $\begin{array}{l}\text { Lack of motivation in the sense of an absence of self-initiated behaviour, mani- } \\
\text { festing on the levels of cognition, behaviour and emotions. This limits active } \\
\text { participation in social activities and therapeutic interventions }\end{array}$ \\
\hline Pain [15] & $\begin{array}{l}\text { Acute: an unpleasant sensory and emotional experience which originates from } \\
\text { actual/potential tissue damage or can be described with such terms; sudden or } \\
\text { gradual onset in an intensity ranging from mild to severe, with a foreseeable/ } \\
\text { unforeseeable end and a duration of less than } 6 \text { months } \\
\text { Chronic: pain that persists for more than } 6 \text { months and is accompanied by } \\
\text { other psychological and/or physical disorders such as anxiety states }\end{array}$ \\
\hline $\begin{array}{l}\text { Breathing abnor- } \\
\text { malities [15] }\end{array}$ & $\begin{array}{l}\text { Abnormalities such as shortness of breath associated with suffocation and/or } \\
\text { the use of respiratory muscles and/or cyanosis and which may be accompa- } \\
\text { nied by rales }\end{array}$ \\
\hline $\begin{array}{l}\text { Feeding prob- } \\
\text { lems [15] }\end{array}$ & $\begin{array}{l}\text { Loss of appetite or lack of interest in food; nausea; weakness of swallowing and } \\
\text { chewing muscles; swallowing difficulties; low level of daily food or fluid intake } \\
\text { which is below the recommended amount and is accompanied by uninten- } \\
\text { tional weight loss ( } \geq 5 \% \text { in } 1 \text { month; } \geq 10 \% \text { in } 6 \text { months) } \\
\text { and/or } \\
\text { rejection of drinks offered, excessive extrarenal water loss (sweating, vomiting, } \\
\text { diarrhoea) }\end{array}$ \\
\hline $\begin{array}{l}\text { Unusual behav- } \\
\text { iour [17] }\end{array}$ & $\begin{array}{l}\text { General descriptions and signs of challenging behaviour which cannot be } \\
\text { clearly allocated to agitation, aggression, apathy, negativity, disruption in the } \\
\text { night, constant attention-seeking, irritability, loss of inhibition, abnormal mo- } \\
\text { tor behaviour, throwing objects, unexplained shouting and socially unaccept- } \\
\text { able behaviour }\end{array}$ \\
\hline $\begin{array}{l}\text { Mobility difficul- } \\
\text { ties [15] }\end{array}$ & $\begin{array}{l}\text { Restriction in the ability to independently change position or location, or in the } \\
\text { purposeful movement of the body or a body part, or in the independent use of } \\
\text { a wheelchair }\end{array}$ \\
\hline Agitation [18] & $\begin{array}{l}\text { Agitation with increased tension and increased psychomotor activity such as } \\
\text { frequently asking questions or complaining }\end{array}$ \\
\hline $\begin{array}{l}\text { Depressive epi- } \\
\text { sodes }[19,20,21]\end{array}$ & $\begin{array}{l}\text { Depressed mood and significant reduction in level of interest, persisting for at } \\
\text { least } 2 \text { weeks. Mood occurs in combination with at least four of the following } \\
\text { signs: loss of weight and appetite, inability to sleep/increased sleep, psycho- } \\
\text { motor restlessness/slowing down, fatigue/lack of energy, feelings of worthless- } \\
\text { ness/guilt, problems concentrating and making decisions, preoccupation with } \\
\text { death, suicidal thoughts or actions }\end{array}$ \\
\hline $\begin{array}{l}\text { Sleep distur- } \\
\text { bances [15] }\end{array}$ & $\begin{array}{l}\text { Interruption of duration and quality of sleep having an impact on daily life, e.g. } \\
\text { mood changes, difficulties in concentrating }\end{array}$ \\
\hline Infections & Infection is identified and signs of infection such as fever are present \\
\hline $\begin{array}{l}\text { Decubitus ulcers } \\
\text { [15] }\end{array}$ & Grade $1-4$ skin irritations \\
\hline Hospitalisation & Hospital stays of more than $24 \mathrm{~h}$ \\
\hline
\end{tabular}

mented findings and perceptions of caregivers and are operationalised as follows: existing yes/no; frequency during the observation period; course documented yes/ no; number of days per period of observation; intensity, such as pain intensity; minimum and maximum level in the respective subperiod; assessment made by healthcare professional/care assistant/ next of kin/doctor; medication interventions yes/no-if so, which; non-medica-

\section{Ethical guidelines}

The study was authorised by the Ethics Committee of the Canton of Zurich (KEK No. 2012-0196) and the Federal Expert Commission for Professional Secrecy in Medical Research.

\section{Data analysis}

The anonymised nursing records were statistically analysed using IBM SPSS version 20.0 to include descriptive analyses, in particular frequencies and main trends. Secondary bivariant correlation analyses were run to explore possible correlations.

All documents were scanned by two separate coders. The two data sets were then automatically compared and the divergences between the data sets listed. A final manual check was made and the data were compared with the anonymised nursing records. Correction of the datasets was only necessary where there were missing values (Missing Completely at Random, MCAR). In this study, the method of case-by-case exclusion was applied [22].

\section{Results}

The first section gives details of the study population and the second section presents the results for the ten most frequently identified symptoms. Since drug interventions influence the extent of symptoms, they are always mentioned where they are clearly assignable to a particular symptom. Finally, we focus on some distinctive features in the last 7 days of life.

\section{Study population}

A total of 320 people (68\%) living in the nursing homes studied died in the years 2011 and 2012. The existence of a dementia disorder was recorded in the nursing records by a nursing professional in 65 cases $(20 \%)$.

In the majority of cases analysed, the type of dementia was not specified in the records $(64.7 \%, \mathrm{n}=33)$. There were 49 women $(75.4 \%)$. The average age was 83.71 years ( $\mathrm{SD} \pm 8.50$ ) and the average length of stay in the nursing home was 3.5 years ( 41.5 months, SD 
\pm 37.30 months). Most of them died in the nursing home $(96.9 \%, \mathrm{n}=63)$; only 2 people (3.1\%) died in hospital. The majority of the study group lived in their own room (71.4\%, $\mathrm{n}=45$; $\bullet$ Tab. 3 ).

\section{Prevalence of symptoms}

Ten frequent symptoms could be identified for the last 90 days of life (• Fig. 1). What stands out is that mobility and feeding problems, unusual behaviours, sleep disturbances and pain occur in at least every second dementia sufferer. Apart from agitation, apathy and depressive episodes, it was not possible to further specify unusual behaviours, as the descriptions in the nursing records did not permit this. However, agitation was the most frequent symptom of unusual behaviour (38.7\%) documented in these records. Breathing abnormalities, apathy and agitation can be observed in every fourth person, and every fifth person also lives with anxiety. Symptoms of depression were the least documented.

\section{Course of symptoms}

Two distinct patterns of symptoms were identified over the last 90 days of life:

- Symptoms occurring with increasing frequency (crescent pattern): anxiety, apathy, breathing abnormalities, feeding problems and pain.

- Symptoms occurring with decreasing frequency (decrescent pattern): unusual behaviours, mobility difficulties, sleep disturbances, agitation and depressive episodes.

Pain, unusual behaviour, mobility constraints and insomnia were continuously present across all four study periods in more than half of the subjects studied. Pain played a particular role, rising continuously over all four points of data collection. A cluster analysis did not reveal any differences between the nursing homes.

\section{Pattern 1-increasing symptoms}

Fear increased by $10 \%$ until the point of data collection $\mathrm{T} 3$, but decreased in $\mathrm{T} 4$ by approximately $5 \%$. Those with anxiety $(10.9 \%, \mathrm{n}=7)$ received medication to re-

Z Gerontol Geriat 2015 · 48:176-183 DOI 10.1007/s00391-014-0668-Z

(c) Springer-Verlag Berlin Heidelberg 2015

\section{A. Koppitz · G. Bosshard · D.H. Schuster $\cdot$ H. Hediger $\cdot$ L. Imhof Type and course of symptoms demonstrated in the terminal and dying phases by people with dementia in nursing homes}

\section{Abstract}

Background. In all, $39 \%$ of people living in Swiss nursing homes suffer from dementia. Detailed data about type and course of symptoms displayed by these patients in their terminal phase are lacking.

Methods. This descriptive, retrospective study analysed 65 nursing documents from deceased people with dementia in four nursing homes in the canton of Zurich, Switzerland.

Results. Difficulties with mobility (81\%), pain $(71 \%)$ and sleep disturbance (63\%) were the most frequent of the 10 identified symptoms. Towards the end of life, difficulties with mobility, sleep disturbance, agitation and other neuropsychiatric symptoms, such as episodes of depression, decreased (decrescent pattern), while pain, feeding problems, breathing abnormalities, apathy and anxiety increased (crescent pattern). Courses of pain were documented in $17 \%$ of the nursing records. In addition, $76 \%$ of the residents had been visited on a daily basis by next of kin in their last 7 days, compared with only one third of residents previously. Furthermore, daily communication between healthcare professionals and next of kin tripled during this period.

Conclusion. The documented prevalence of a high and increasing level of pain towards the end of life, combined with the lack of documented courses of pain, shows potential for improvement in pain relief and pain identification for patients with dementia in their terminal phase. The increasing number of visits by next of kin and the increasingly intensive contact between healthcare professionals and next of kin in the last 7 days are a strong indicator that the end of life can be predicted relatively well by the involved participants and appropriate reactions follow.

\section{Keywords}

Dementia · Nursing home · Symptoms .

Palliative care $\cdot$ Terminal phase

\section{Symptome und Symptomverläufe bei Menschen mit Demenz in der Terminal- und Sterbephase in Pflegeheimen}

\section{Zusammenfassung}

Hintergrund. In Schweizer Pflegeheimen leben etwa 39\% demenzerkrankte Personen. Es fehlen konkrete Daten über Symptome und Symptomverläufe dieser Personen in der Terminalphase.

Methode. Mit einem deskriptiv-retrospektiven Design wurden im Rahmen der Pallhome-Studie 65 Pflegedokumente von verstorbenen demenzerkrankten Personen aus 4 Heimen im Kanton Zürich, Schweiz analysiert.

Ergebnisse. Mobilitätsschwierigkeiten (81\%), Schmerzen (71\%) und Schlafstörungen (63\%) waren die häufigsten der insgesa$\mathrm{mt} 10$ identifizierten Symptome. Zum Lebensende hin nahmen Mobilitätsschwierigkeiten, Schlafstörungen, Agitation und andere Verhaltensauffälligkeiten sowie depressive Episoden ab (Decrescendomuster), während Schmerzen, Ernährungsschwierigkeiten, Atemauffälligkeiten, Apathie sowie Angst häufiger wurden (Crescendomuster). Schmerzverläufe waren bei $17 \%$ der Personen in den Pflegeakten dokumentiert. In den letzten 7 Lebenstagen waren $76 \%$ der untersuchten Verstorbenen von ihren Angehörigen täglich besucht worden, was vorher in weniger als einem Drittel der Fall war. Der tägliche Austausch zwischen Pflegepersonen und Angehörigen verdreifachte sich. Schlussfolgerungen. Die dokumentierte hohe und gegen das Lebensende hin noch ansteigende Schmerzprävalenz im Zusammenhang mit dem Fehlen von dokumentierten Schmerzverläufen zeigt ein mögliches Verbesserungspotenzial im Bereich der systematischen Schmerzerkennung und -bekämpfung bei demenzerkrankten Personen am Lebensende. Die steigende Zahl an Besuchen und der zunehmend intensive Kontakt zwischen Pflege und Angehörigen in den letzten 7 Lebenstagen sind ein starker Hinweis, dass das Lebensende von allen Beteiligten gut prognostiziert werden kann und entsprechende Reaktionen erfolgen.

Schlüsselwörter

Demenz · Pflegeheim · Symptome · Palliative Care $\cdot$ Terminalphase 
Tab. 3 Study population

\begin{tabular}{|llll}
\hline Characteristics of the study population $(\mathbf{n}=65)$ & Mean \pm SD & $\mathbf{n}$ & $\%$ \\
\hline Age at time of death, female & $87.12 \pm 6.87$ & 49 & 75.4 \\
\hline Age at time of death, male & $80.31 \pm 10.14$ & 16 & 24.6 \\
\hline Length of stay (months) & $41.51 \pm 37.30$ & 65 & 100.0 \\
\hline SD standard deviation. & & &
\end{tabular}

lieve it, with the administration of drugs doubling in T4.

In contrast, apathy was particularly prominent in survey period T4 $(46.2 \%$, $\mathrm{n}=30$ ). The frequency of apathetic behaviour quadrupled between $\mathrm{T} 1$ and $\mathrm{T} 4$.

Breathing abnormalities were particularly prominent in the 4th survey period (T4: $50.8 \%, n=33$ ) and can be associated with imminent death. Since breathing abnormalities can occur if pneumonia is present, the prevalence of pneumonia was also studied. Three people (4.6 and $4.7 \%$ respectively) were treated for pneumonia in the data collection periods from $\mathrm{T} 2$ to $\mathrm{T} 4$.

Loss of appetite or swallowing difficulties were particularly prominent in the third survey period (T3: 75.4\%, $\mathrm{n}=49$ ). Urinary tract infections as a possible consequence of a fluid deficit occurred in up to $17.2 \%$ of the people $(n=11, T 2)$.

Pain increased steadily over the four survey periods (T1: $64.2 \%, \mathrm{n}=34$; $\mathrm{T} 2$ : 67.3\%, $\mathrm{n}=33$; T3: $72.5 \%, \mathrm{n}=37$; T4: $80.4 \%$, $n=41$ ), with four fifths of those affected experiencing pain in the last week of life. However it was hardly possible to differentiate between acute and chronic pain in the nursing documents. The progression of pain was only documented for 11 people. In all study periods, $36 \%$ of men were documented without pain, compared with only $13.5 \%$ of women. People with a documented pain event (T1: 64.2\%, $\mathrm{n}=34$; T2: $67.3 \%, n=33$; T3: $72.5 \%, n=37$; T4: $80.4 \%, \mathrm{n}=41$ ) received pain medication significantly more frequently than those without a documented pain event (T1: $35.8 \%, \mathrm{n}=19 ; \mathrm{T} 2: 32.7 \%, \mathrm{n}=16$; T3: $27.5 \%$, $\mathrm{n}=14$; T4: 19.6\%, $\mathrm{n}=10$; Fisher's exact test $\mathrm{p}=0.000$, phi $=0.702$ ). Paracetamol and morphine were the most frequently administered drugs for pain. Morphine was the most commonly administered on demand drug, followed by trazodone and domperidone. Morphine and trazodone were administered significantly more of- ten as an on demand drug to people who were older than 85 years than to people under 85 years of age. More pain events were documented for those cared for by their family doctor than for those cared for by the nursing home's own doctor ( $80.5 \%$ family doctor vs. $19.5 \%$ nursing home doctor).

In this study, $27 \%(\mathrm{n}=13)$ of people with dementia lived with three symptoms. No other gender differences apart from those reported above were found. Details of this symptom pattern are available in $\bullet$ Fig. 2.

\section{Pattern 2-decreasing symptoms}

The category "unusual behaviours" contains general descriptions and signs of challenging behaviour, since the nursing records did not permit clear assignment or categorisation as described by [17]. Unusual behaviour was documented in more $\mathrm{n}=43$; T2: $59.4 \%, \mathrm{n}=38$; T3: $61.5 \%, \mathrm{n}=40$; T4: $60 \%, n=39$ ). There was no documented record of the extent to which these behavioural abnormalities might have been associated with delirium.

Mobility difficulties were documented for approximately three quarters of patients (T1: 85.9\%, $\mathrm{n}=55$; T2: 79.7\%, $\mathrm{n}=51$; T3: $84.6 \%, n=55$; T4: 73.8\%, $n=48$ ). A detailed description of the mobility restrictions-such as the number of steps the patient could take or how much help was needed for transfer-was largely lacking in the nursing documents. The incidence of decubitus ulcers as a possible complication of a mobility limitation doubled over the four study periods (T1: $26.6 \%, \mathrm{n}=17$; T4: $52.3 \%, n=34)$. The number of infected wounds dropped during the last 90 days of life (T1: $7.8 \%, \mathrm{n}=5 ; \mathrm{T} 4: 3.1 \%, \mathrm{n}=2$ ). The results show a decreasing pattern of sleep disturbance between survey periods T1 $(60.3 \%, \mathrm{n}=38)$ and $\mathrm{T} 4(56.5 \%, \mathrm{n}=35)$. At least one fifth of dementia sufferers received drug interventions for sleep disthan half the people studied (T1: $67.2 \%$, turbance (T1: $40.6 \%, \mathrm{n}=26 ; \mathrm{T} 4: 21.5 \%$, $\mathrm{n}=14$ ).

Agitated behaviour decreased from $\mathrm{T} 1$ to $\mathrm{T} 4$ by almost half (T1: $41.9 \%, \mathrm{n}=26$; $\mathrm{T} 4$ : $23.0 \%, n=14)$. Depressive episodes were recorded in approximately one fifth of people suffering from dementia in their third-to-last month of life (T1: 20.4\%, $\mathrm{n}=11$ ), ultimately dropping to $2 \%$ (T2 and T3: $15.7 \%, \mathrm{n}=8 ; \mathrm{T} 4: 2.0 \%, \mathrm{n}=1$ ). A change or reduction in medication to combat depressive episodes was not documented (T1: 34.4\%, n=22; T4: 32.3\%, $\mathrm{n}=14$ ).

The number of drug interventions, including antibiotic therapy, halved over the four survey periods (T1: $20.3 \%, \mathrm{n}=13$; $\mathrm{T} 4$ : $10.8 \%, \mathrm{n}=7$ ). Hospital referrals were only documented at the point of data collection $\mathrm{T} 2(3.1 \%, \mathrm{n}=2)$.

There were two persons living with none of the five symptoms in symptom pattern $2(\mathrm{n}=41)$. In addition, no person was affected by all five symptoms simultaneously. No other gender differences were found. Details of this symptom pattern are shown in $\bullet$ Fig. 3.

\section{Distinctive features in the last 7 days of life}

Healthcare professionals and next of kin provided closeness, company and support. The total number of visits increased by approximately $15 \%$ up to the day of death (T1: 65.6\%, $\mathrm{n}=42 ; \mathrm{T} 4: 80.0 \%, \mathrm{n}=52$ ). Particularly striking is the increase in the number of daily visits (T1:21.4\%, $\mathrm{n}=9$; $\mathrm{T} 4$ : $75.9 \%, n=41$; Fig. 4). Only one person died alone; the majority were attended by their next of kin $(58.8 \%, \mathrm{n}=10)$ or by caregivers $(35.3 \%, \mathrm{n}=6)$.

An important factor for the caregivers was the interaction with the family, which intensified over the last 7 days of life (T4) (T1: 60.9\%, $\mathrm{n}=39$; $\mathrm{T} 4: 89.2 \%, \mathrm{n}=58$ ). In $\mathrm{T} 4$, daily family involvement was three times more frequent than in $\mathrm{T} 1$ (T1: $7.7 \%$, $\mathrm{n}=3$; T4: $25.9 \%, \mathrm{n}=15$ ). The interaction between caregivers and the medical service was also very marked in the end phase $(\mathrm{T} 1: 75.0 \%, \mathrm{n}=48$; $\mathrm{T} 2: 84.4 \%, \mathrm{n}=54$; T4: $81.5, n=53)$. All this data strongly indicates that the nursing team and the family members very often realise when a resident is entering the dying phase and react accordingly. 


\section{Originalien}

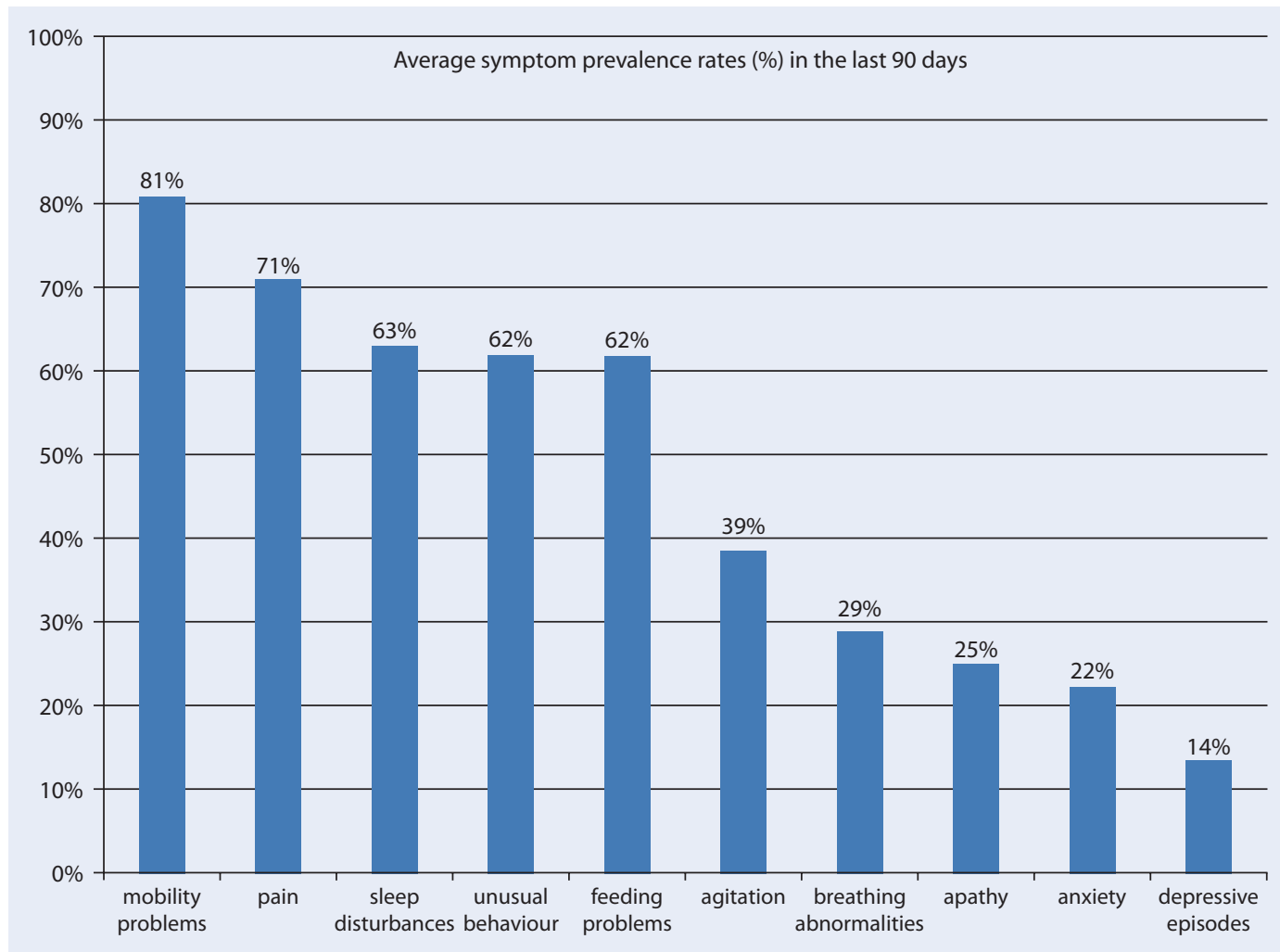

Fig. $1 \varangle$ Prevalence of symptoms (in \%)

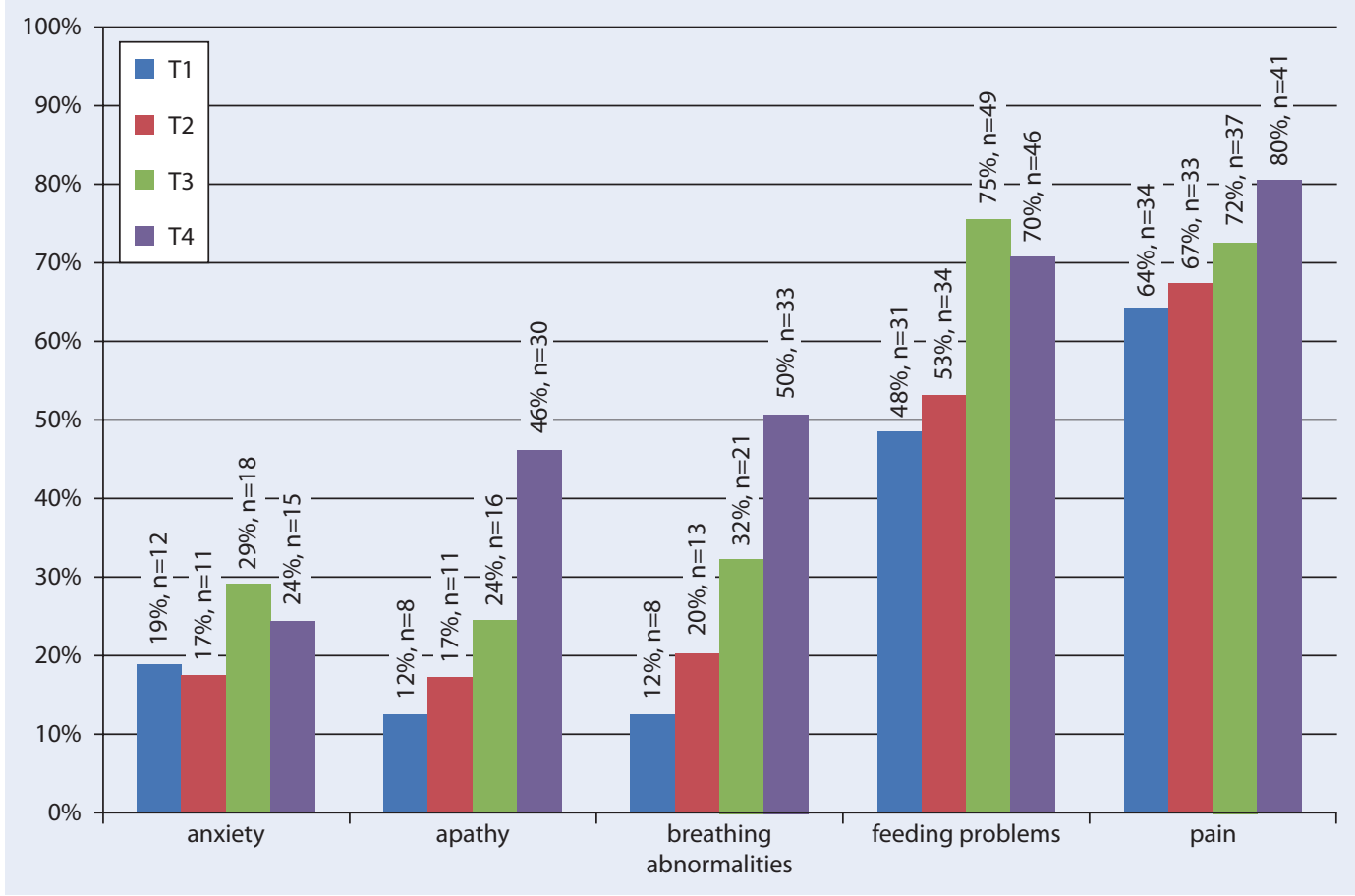

Fig. $2<$ Pattern 1 increasing symptoms

The reduction in psychosocial stresses in the last week of life (T1: 17.2\%; T3: 21.5\%; T4: $12.3 \%$ ) suggests that the dying phase is experienced as intense, but less stressful for the patients than the preceding phase. Only rarely was a member of the clergy called in during the dying phase $(9.2 \%, \mathrm{n}=6)$.

In view of the apparent ability to estimate when death is imminent, some, but not all, therapies were adapted to the dying phase. Physiotherapy treatment was suspended and the administration of antibiotics reduced by half. Similarly, no nutrition or fluids were administered via percutaneous endoscopic gastroscopy (PEG), no new PEG was inserted, and no patient was referred to a hospital. Recoding of the 


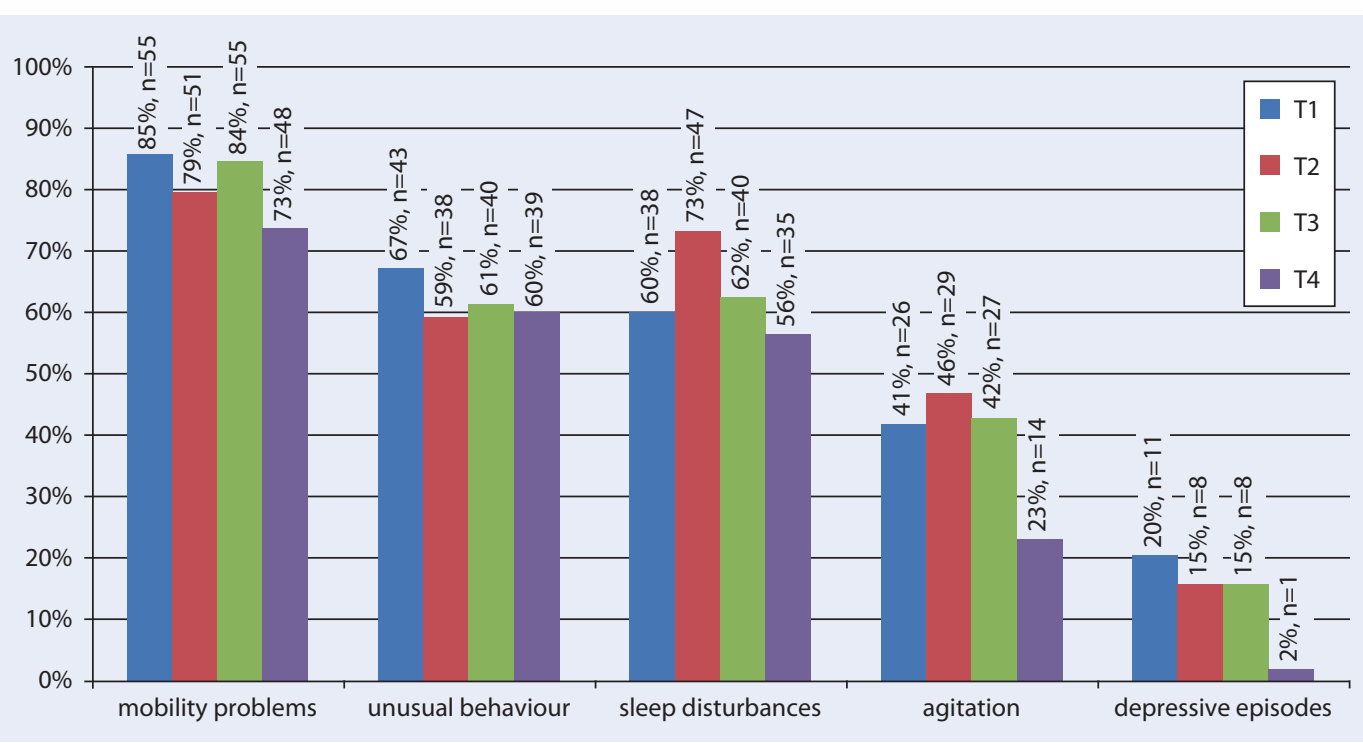

Fig. $3<$ Pattern 2decreasing symptoms

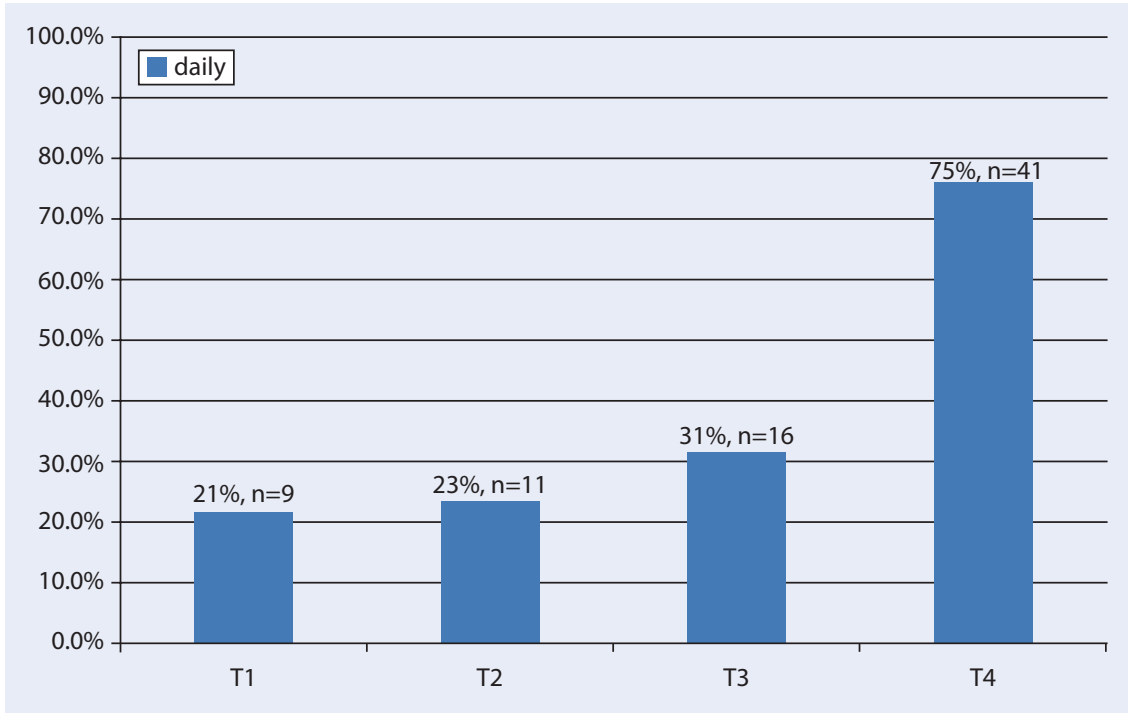

Fig. $4 \Delta$ Increasing visits

amount of liquid drunk and a more than $20 \%$ increase in oral hygiene suggest sensitivity on the part of the caregivers to the need to moisten the oral mucosa. However, except in three cases, all prescribed medications continued to be administered until the day of death.

\section{Discussion}

The ten symptoms identified for people suffering from dementia are similar to those described in the literature for cancers and chronic diseases such as chronic obstructive pulmonary disease (COPD) or for cardiovascular diseases [23, 24, 25, $26,27,28,29,30]$. Pain, breathing abnor- malities, feeding and drinking difficulties and mobility restrictions, including being bedridden, occur in the terminal phase of all illnesses. Remarkably, despite the quite different end-of-life trajectories for dementia (frailty), chronic diseases such as COPD (organ system failure) and malignant diseases (terminal disease) [31], the symptoms that occur in the terminal phase are actually quite similar.

The only exception is unusual behaviour. This can be designated a typical symptom of dementia, even in the terminal phase $[9,26]$, and occurs in more than $90 \%$ of patients $[7,32,33,34]$. In contrast, this study was unable to identify symptoms of delirium, which can often occur in the terminal phase [35]. This is presumably due to the fact that it is more difficult for nurses to identify symptoms of delirium in people with dementia [36].

Familiarity with and recognition of these symptoms is a prerequisite for initiating palliative measures [10]. In progressive incurable diseases such as dementia, the assessment of symptoms plays a key role in palliative care and general care, but this is often complicated by the lack of verbal communication in those affected $[37,38,39]$. The increasing prevalence of pain in the last 90 days of life found in this study indicates that pain is obviously recognised but the progression of pain is only documented in 11 of the 65 people and the prescribed pain medication is not sufficient to provide adequate pain relief. Lunney [40] talks about the need for differentiation and precision in critical thinking. Clear, careful, considered, problem-focused, multi-method action that takes into account the depth of the problem is based on questioning, acknowledging, observing and examining the affected patient and his/her next of kin, and is not an ability ascribed to one particular professional group [41,40]. Healthcare professionals perceive symptoms with all human senses (seeing, hearing, smelling, tasting, touching). This is necessary in order to identify when something does not reflect the habits of the person with dementia. Observing (attentive, able to collect and differentiate information), naming (describe, use of terms, language) and 
the verbal and non-verbal exchange with the person concerned, his family, and professional colleagues helps to explain and understand symptoms [41]. The study results point to a need for action in improving the recognition of symptoms.

It is undisputed that standardized assessment tools can be useful [42]. They can facilitate an interpretation of what has changed, but assessment tools cannot make decisions or take action. However, the decisive factor in symptom recognition and interpretation is the healthcare professional, since only he/she can validate and prioritise the symptoms to alleviate suffering. Well-educated healthcare professionals working in long-term care can significantly help avoid or alleviate suffering [43]. In this context it remains questionable whether there are currently enough well-qualified health professionals in Swiss nursing homes.

Another noteworthy result of this study is that the data do not confirm the uncertainty about prognosis of an advanced chronic illness, as discussed by Sorenson [44], in the case of dementia. Rather, the study results indicate that the healthcare professionals and the family clearly notice specific changes in people with dementia in the dying phase. This is documented by the high frequency of visits by next of kin in the last 7 days of life and the intensified interaction of healthcare professionals with the next of kin, but also with the medical service. We must question the relevance of prognostic instruments for predicting time left to live, including a prediction of the symptom burden $[12,45,46$, 47] for the dying phase in dementia sufferers, in terms of timing and indication.

Furthermore, the small number of hospitalisations and wound infections (approximately $10 \%$ ) indicated that observation of symptoms and interprofessional communication with the medical service takes place. This is in contrast to the complications and invasive measures described in the literature $[48,49,50]$. No significant correlation between the form of medical care (nursing home doctor or family doctor) and the identification of symptoms was observed. However, fewer pain events were documented for patients in the care of a nursing home doctor. This could be an indication that health pro- fessionals who are continuously present, suitably qualified and possess in-depth knowledge specific to the target group can provide improved quality of care. Singh et al. [51] describe limits and errors in medi$\mathrm{cal}$ assessment and treatment planning in primary care. According to them, symptoms go unnoticed or are misinterpreted in one out of ten cases. The assessment of symptoms and reduction of the burden caused by symptoms should not be restricted to representatives of a single profession, but rather should be carried out by well-trained health professionals with qualified skills in clinical assessment.

\section{Limitations}

The significance of this study is limited due to its retrospective design using a convenience sample. Significance is also limited by the quality and heterogeneity of the information from the nursing records. It is difficult to distinguish primary disease symptoms from treatment-related side effects. For instance, the administration of morphine can result in apathy, apathy in turn can reduce the drive for mobility, which leads to the confinement to bed, which could then be perceived as decreased difficulty with mobility at the end of life. The fact that no other cluster effects were observed may be related to the small sample.

\section{Conclusion for practice}

People suffering from dementia and their next of kin depend on well-qualified health professionals in nursing homes, which implies a need for an increase in basic care provided by nursing and medical professionals.

Despite financial constraints, opportunities for exchange - such as hand-over reports, discussions of cases, family meetings and expert discussions-should be intensified in order to exploit the broad base of knowledge within the treatment team, in combination with the family members, in a resource-oriented way.

\section{Conclusion for research}

Using prominent symptoms such as mobility difficulties, pain, unusual behaviours and feeding problems, we need to examine whether the deployment of well-trained specialists could contribute towards a significant reduction in these symptoms in dementia sufferers in Switzerland. A larger sample would make it possible to determine which symptoms often occur together.

\section{Corresponding address

A. Koppitz
Institute of Nursing, Zurich
University of Applied Sciences
(ZHAW)
Technikumstr. 71,
8404 Winterthur
Switzerland
andrea.koppitz@zhaw.ch

External funding. Swiss Alzheimer's Association, Trust Fund of the Zurich School for Nurse Education.

Acknowledgements. We would like to thank the four practice partners, the Swiss Alzheimer's Association and the Trust Fund of the Zurich School for Nurse Education for their support and assistance with this study. We would also like to thank MSc students Nina Braun, Ursula Heinrich and Ramona Odermatt for their contributions to the study.

\section{Compliance with ethical guidelines}

Conflict of interest. A. Koppiz, G. Bosshard, D. Händler Schuster, H. Hediger and L. Imhof state that there are no conflicts of interest. All studies on humans described in the present manuscript were carried out with the approval of the responsible ethics committee and in accordance with national law and the Helsinki Declaration of 1975 (in its current, revised form). Informed consent was obtained from all patients included in studies.

\section{References}

1. Schweizer Alzheimervereinigung (2009) 102 '000 Menschen mit Demenz in der Schweiz. http:// www.alzheimerurischwyz.ch/udoc/74.pdf. Accessed 06 Jun 2014

2. Bundesamt für Statistik (2010) Gesundheitszustand von betagten Personen in Institutionen 2008/09. http://www.bfs.admin.ch/bfs/portal/de/index/themen/14/02/01/key/07/03.html. Accessed 06 Jun 2014

3. Houttekier D, Cohen J, Bilsen J et al (2010) Place of death of older persons with dementia. A study in five European countries. J Am Geriatr Soc 58:751756 
4. Mitchell SL, Teno J, Miller SC, Mor V (2005) A national study of the location of death for older persons with dementia. J Am Geriatr Soc 53:299-305

5. Bundesamt für Statistik (2013) Todesursachenstatistik - Sterblichkeit und deren Hauptursachen in der Schweiz. http://www.bfs.admin. ch/bfs/portal/de/index/news/publikationen. html?publicationID=5176. Accessed 06 Jun 2014

6. Bundesamt für Statistik (2006) Szenarien zur Bevölkerungsentwicklung der Schweiz: 2005-2050. http://www.bfs.admin.ch/bfs/portal/de/index/ themen/01/22/publ.html?publicationID=2411. Accessed 06 Jun 2014

7. Aminoff BZ, Adunsky A (2004) Dying dementia patients: too much suffering, too little palliation. Am J Alzheimers Dis Other Demen 19:243-247

8. Aminoff BZ, Adunsky A (2006) Their last 6 months: suffering and survival of end-stage dementia patients. Age Ageing 35:597-601

9. Steen JT van der (2010) Dying with dementia: what we know after more than a decade of research. J Alzheimers Dis 22:37-55

10. Schweizerische Gesellschaft für Palliative Medizin Pflege und Begleitung (2012) Kompetenzen für Spezialisten in Palliative Care. http://www.palliative.ch/fileadmin/user_upload/palliative/fachwelt/ E_Standards/Kompetenzkatalog_DE.pdf. Accessed 06 Jun 2014

11. Polit DF, Beck CT (2012) Nursing research: generating and assessing evidence for nursing practice. Wolters Kluwer Health/Lippincott Williams \& Wilkins, Philadelphia, pp 276-277

12. Kiely DK, Shaffer ML, Mitchell SL (2012) Scales for the evaluation of end-of-life care in advanced dementia: sensitivity to change. Alzheimer Dis Assoc Disord 26:358-363

13. Volicer L, Hurley AC, Blasi ZV (2001) Scales for evaluation of end-of-life care in dementia. Alzheimer Dis Assoc Disord 15:194-200

14. Dodd M, Janson S, Facione N et al (2001) Advancing the science of symptom management. J Adv Nurs 33:668-676

15. Doenges ME, Frances MM, Alice M (2013) Pflegediagnosen und Pflegemassnahmen. Huber, Bern

16. Treusch Y, Jerosch D, Majic T et al (2010) How can we provide better services for demented nursing home residents suffering from apathy? Psychiatr Prax 37:84-88

17. Cummings JL (2009) Neuropsychiatric InventoryNursing Home Version (NPI-NH). Comprehensive assessment of psychopathology in patients with dementia residing in nursing homes. http://www. livinglongerlivingbetter.gov.au/internet/living/ publishing.nsf/Content/1CC5715F37B20521CA25 7B9C001B2D13/\$File/NPI-NH\%20assessment $\% 20$ tool.pdf. Accessed 06 Jun 2014

18. Testad I, Aasland AM, Aarsland D (2007) Prevalence and correlates of disruptive behavior in patients in Norwegian nursing homes. Int J Geriatr Psychiatry 22:916-921

19. Deutsche Gesellschaft für Psychiatrie Psychotherapie und Nervenheilkunde, Deutsche Gesellschaft für Neurologie (2009) S3-Leitlinie Demenzen. $\mathrm{http}: / /$ www.google.ch/url?sa=t\&rct=j\&q=\&esrc=s \&source $=$ web\&cd $=1 \&$ sqi $=2 \&$ ved $=0 C C g Q F j A A \& u r$ I=http $\% 3$ A\%2F\%2Fwww.dgn.org\%2Fimages\%2F stories\%2Fdgn\%2Fpdf\%2Fs3_leitlinie_demenzen. pdf\&ei=BIQTU5HINYeS7AaU-oDQCw\&usg=AFQjC NGIgIGTI7BdQulLcSNdzwhWwB7h2w\&bvm=bv. 6 1965928,bs.1,d.bGE. Accessed 20. June 2012
20. Sass H, Wittchen H-U, Zaudig M et al (1998) Diagnostisches und statistisches Manual psychischer Störungen, DSM-IV: übersetzt nach der vierten Auflage des Diagnostic and statistical manual of mental disorders der American Psychiatric Association. Hogrefe, Göttingen

21. Thalmann A, Morfeld M, Benthien A (2012) Anxiety and depression in the elderly: results of a regional examination. Gesundheitswesen 74:29-33

22. Bortz J (2005) Statistik für Human- und Sozialwissenschaftler. Springer, Heidelberg

23. Bausewein C (2005) Symptome in der Terminalphase. Onkologe 11:420-426

24. Jaarsma T, Beattie JM, Ryder M et al (2009) Palliative care in heart failure: a position statement from the palliative care workshop of the Heart Failure Association of the European Society of Cardiology. Eur J Heart Fail 11:433-443

25. Marchetti P, Voltz R, Rubio C et al (2013) Provision of palliative care and pain management services for oncology patients. J Natl Compr Canc Netw 11:17-27

26. Mitchell SL, Teno J, Kiely D et al (2009) The clinical course of advanced dementia. N Engl J Med 361:1529-1538

27. Oechsle K, Goerth K, Bokemeyer C et al (2013) Symptom burden in palliative care patients: perspectives of patients, their family caregivers, and their attending physicians. Support Care Cancer 21:1955-1962

28. Pinnock H, Kendall M, Murray SA et al (2011) Living and dying with severe chronic obstructive pulmonary disease: multi-perspective longitudinal qualitative study. BMJ Support Palliat Care 1:174-183

29. Steen JT van der, Ribbe MW (2007) Dying with dementia: what do we know about it? Tijdschr Gerontol Geriatr 38:288-297

30. Vandervoort A, Van den Block L, Steen JT van der et al (2013) Nursing home residents dying with dementia in Flanders, Belgium: a nationwide postmortem study on clinical characteristics and quality of dying. J Am Med Dir Assoc 14:485-492

31. Lunney JR, Lynn JR, Foley DJ et al (2003) Patterns of functional decline at the end of life. JAMA 289:2387-2392

32. Cornegé-Blokland E, Kleijer BC, Hertogh C et al (2012) Reasons to prescribe antipsychotics for the behavioral symptoms of dementia: a survey in Dutch nursing homes among physicians, nurses, and family caregivers. J Am Med Dir Assoc 13:80. e81-80.e86

33. Lussier D, Bruneau M-A, Villalpando JM (2011) Management of end-stage dementia. Prim Care 38:247-264

34. Volicer L, Seltzer B, Rheaume Y et al (1989) Eating difficulties in patients with probable dementia of the Alzheimer type. J Geriatr Psychiatry Neurol 2:188-195

35. Leonard M, Raju B, Conroy M et al (2008) Reversibility of delirium in terminally ill patients and predictors of mortality. Palliat Med 22:848-854

36. Fick DM, Hodo DM, Lawrence F et al (2007) Recognizing delirium superimposed on dementia: assessing nurses' knowledge using case vignettes. J Gerontol Nurs 33:40-47

37. Herr K, Bjoro K, Decker S (2006) Tools for assessment of pain in nonverbal older adults with sementia: a state-of-the-science review. J Pain Symptom Manage 31:170-192

38. Smith M (2005) Pain assessment in nonverbal older adults with advanced dementia. Perspect Psychiatr Care 41:99-113
39. World Health Organization (2011) Palliative care for older people: better practices. http://www.euro.who.int/en/what-we-publish/abstracts/palliative-care-for-older-people-better-practices. Accessed 06 Jun 2014

40. Lunney M (2010) Use of critical thinking in the diagnostic process. Int J Nurs Terminol Classif 21:8288

41. Jarvis C (2008) Physical examination and health assessment. Saunders/Elsevier, St. Louis

42. Wilkinson JM (2011) Nursing process and critical thinking. Pearson, New York

43. Donald F, Martin-Misener R, Carter N et al (2013) A systematic review of the effectiveness of advanced practice nurses in long-term care. J Adv Nurs 69:2148-2161

44. Sorenson HM (2013) Improving end-of-life care for patients with chronic obstructive pulmonary disease. Ther Adv Respir Dis 7:320-326

45. Kiely DK, Volicer L, Teno J et al (2006) The validity and reliability of scales for the evaluation of endof-life care in advanced dementia. Alzheimer Dis Assoc Disord 20:176-181

46. Soest-Poortvliet MC van, Steen JT van der, Zimmerman S et al (2012) Psychometric properties of instruments to measure the quality of end-of-life care and dying for long-term care residents with dementia. Qual Life Res 21:671-684

47. Soest-Poortvliet MC van, Steen JT van der, Zimmerman S et al (2011) Measuring the quality of dying and quality of care when dying in longterm care settings: a qualitative content analysis of available instruments. J Pain Symptom Manage 42:852-863

48. Chen J, Lamberg JL, Chen Y et al (2006) Occurrence and treatment of suspected pneumonia in longterm care residents dying with advanced dementia. J Am Geriatr Soc 54:290-295

49. Givens JL, Selby K, Goldfeld KS et al (2012) Hospital transfers of nursing home residents with advanced dementia. J Am Geriatr Soc 60:905-909

50. Steen JT van der, Pasman HRW, Ribbe MW et al (2009) Discomfort in dementia patients dying from pneumonia and its relief by antibiotics. Scand $\mathrm{J}$ Infect Dis 41:143-151

51. Singh H, Giardina T, Meyer A et al (2013) Types and origins of diagnostic errors in primary care settings. JAMA 173:418-425 